\title{
Pharmacokinetic Studies on Metoprolol - Eudragit Matrix Tablets and Bioequivalence Consideration with Mepressor $^{\circledR}$
}

\author{
F Rasool ${ }^{1}$, M Ahmad ${ }^{1}$, G Murtaza ${ }^{2}$, HMS Khan ${ }^{1}$ and SA Khan ${ }^{1}$ \\ ${ }^{1}$ Department of Pharmacy, Faculty of Pharmacy and Alternative Medicines, the Islamia University of Bahawalpur, \\ Bahawalpur-63100, ${ }^{2}$ Department of Pharmacy, COMSATS Institute of Information Technology, Abbottabad, Pakistan.
}

\begin{abstract}
Purpose: To investigate the pharmacokinetics of of a developed metoprolol and a reference standard (Mepressor $\left.{ }^{\circledR}\right)$.

Methods: Metoprolol tartrate-loaded Eudragit ${ }^{\Theta}$ FS microparticles were formulated and compressed into tablets. The tablets were tested for their physicochemical properties according to United States Pharmacopoeia (USP) criteria. In vivo studies of the formulations were carried out in 28 young healthy fasting male volunteers based on a randomized open label $4 \times 4$ crossover study design with a washout period of 7 days.

Results: In vitro tests showed that the developed and reference standard of metoprolol tablets met compendia (USP) requirements. Zero order release of drug was observed from all the tablets. In vivo data demonstrated that there were significant $(p<0.05)$ differences in $t_{\max }, C_{\max }, M R T, A U C_{0-t}$, and $A \cup C_{0-\infty}$ between the reference and test (developed) formulations. However, the $90 \%$ class interval for the mean ratios of the In-transformed Cmax, $A \cup C_{0-t}$ and $A U C_{0-a}$ for the reference, T1, T2, and T3 lied in the bioequivalence range (80 to $125 \%$ ) indicating bioequivalence between the compared formulations.

Conclusion: It can be concluded from this single-dose study that the reference and test (developed) formulations met the predetermined criteria for bioequivalence in young healthy fasting male human subjects as the bioequivalence factor lie in the pre-determined limits for bioequivalence. Thus, the two formulations can be considered bioequivalent.
\end{abstract}

Keywords: Metoprolol tartrate, Eudragit ${ }^{\circledR}$ FS, Microparticles, Bioavailability, Pharmacokinetics. 


\section{INTRODUCTION}

$\beta$-blockers, oxprenolol and metoprolol are well absorbed in the colon as well as in the small intestine. Thus, these drugs are good candidates for delivery to colon [1]. Metoprolol is used in the management of cardiovascular disorders such as hypertension and angina pectoris. It is completely absorbed in the intestine after oral administration but exhibits $50 \%$ bioavailability due to extensive first pass effect [2]. The mean time to reach maximum plasma concentration and mean elimination half life for metoprolol after oral dosing are 2 $\mathrm{h}$ and $4 \mathrm{~h}$, respectively. Based on these parameters, metoprolol is administered 3-4 times daily $[3,4]$ which makes it a good candidate for formulation into extended and targeted release dosage form to decrease dosing frequency.

Eudragit $^{\circledR}$ polymers are commercial $\mathrm{pH}$ dependent co-polymers, are available in various ionic grades and have been approved by the Food and Drug Administration (FDA) for colonic drug delivery. Moreover, these polymers also act as both binders and coating materials [5]. Eudragit ${ }^{\circledR}$ FS, a potential $\mathrm{pH}$-dependent carrier for colonic drug delivery, which retards drug release in stomach and small intestine, is a copolymer of methacrylic acid, methyl methacrylate and methyl acrylate [6].

Based on these considerations, this study was designed to develop suitable metoprolol - Eudragit ${ }^{\circledR} F S$ extended and targeted release $\mathrm{pH}$-dependent tablet formulations.

\section{EXPERIMENTAL}

\section{Materials}

Metoprolol tartrate was a gift from Novartis Pharmaceuticals, Karachi, Pakistan. Eudragit $^{\circledR}$ FS was purchased from Rohm Pharma, Darmstadt, Germany. Metoprolol tartrate reference tablets (Mepressor ${ }^{\circledR} 200$ mg, Novartis Pharmaceuticals, Karachi,
Pakistan) was purchased from Survaid Pharmacy, Lahore, Pakistan. Light liquid paraffin, acetone, n-hexane, and other chemicals of analytical grade were procured from Merck, Germany, and were used as received.

\section{Preparation of test tablets}

Metoprolol (1 g) and the copolymer, i.e., Eudragit $^{\circledR}$ FS $(1,1.5$ or $2 \mathrm{~g})$ were dissolved in acetone $(20 \mathrm{ml})$ using a magnetic stirrer (rotating at $450 \mathrm{rpm}$ ) to prepare drug-polymer solution. Light liquid paraffin $(40 \mathrm{ml})$ solution containing Span $80(0.2 \mathrm{~g})$ was added to the drug-polymer solution with continuous stirring for $4 \mathrm{~h}$ at room temperature $\left(32{ }^{\circ} \mathrm{C}\right)$. Following complete removal of acetone, the resultant microparticles were harvested by filtration under vacuum. The microparticles were washed three times with $n$-hexane $(100$ $\mathrm{ml}$ ) and dried in an oven at $40{ }^{\circ} \mathrm{C}$ for $48 \mathrm{~h}$. The microparticles (in drug/polymer ratios of $1: 1, \quad 1: 1.5$ or $1: 2, \quad w / w)$ were directly compressed to tablets coded T1, T2 and T3, respectively, each tablet containing $200 \mathrm{mg}$ of metoprolol.

\section{In vitro tests of tablets}

Evaluation of the weight variation, tablet hardness, friability, disintegration and dissolution of the reference and test tablets were performed.

Six tablets were tested for disintegration in $0.1 \mathrm{M} \mathrm{HCl}$ for $2 \mathrm{~h}$ by using a USP basket rack assembly and then in phosphate buffer $\mathrm{pH}$ 6.8. In vitro dissolution test was conducted by sequential $\mathrm{pH}$ change method using USP dissolution apparatus II to simulate gastrointestinal conditions. Three different dissolution media were used, namely, $0.1 \mathrm{M}$ hydrochloric acid ( $\mathrm{pH} 1.2)$ for $2 \mathrm{~h}$, phosphate buffer $(\mathrm{pH} 4.5)$ for $2 \mathrm{~h}$ and phosphate buffer $(\mathrm{pH} 7.0)$ for $8 \mathrm{~h}$. The volume of the dissolution medium used in each case was $900 \mathrm{ml}$ which was stirred at $50 \mathrm{rpm}$ and $37 \pm$ $0.5{ }^{\circ} \mathrm{C}$. Dissolution samples $(5 \mathrm{ml})$ were withdrawn at $0,1,2,3,4,6,8,10$ and $12 \mathrm{~h}$, 
filtered through a $0.45 \mu \mathrm{m}$ filter and analyzed as described previously [7]. To assess the mode of in vitro drug release from the formulations, the release data were fitted to zero-order, first-order, Higuchi and Korsmeyer-Peppas models $[7,8]$.

\section{Pharmacokinetic tests - protocol and subject criteria}

In vivo study was carried out at the Centre for Bioequivalence Studies, Faculty of Pharmacy and Alternative Medicines, the Islamia University of Bahawalpur, Bahawalpur, Pakistan, after obtaining ethical approval. The heart rate, blood pressure and respiration rate of the human subjects were continuously monitored. Also, ECG and blood, urine and hepatic tests were performed on a regular basis. The subjects were questioned regarding adverse effects experienced during the study (including washout periods) and the responses were recorded on an appropriate format. The principles of Helsinki Declaration [9] and Good Clinical Practice [10] were observed in the conduct of the study. Based on the outcomes of ECG and blood, urine and hepatic tests, twenty eight young healthy fasting male human volunteers age $23.5 \pm$ 4.2 years (range 20 - 30 years), weight $66.7 \pm$ $9.5 \mathrm{~kg}$ (range 59 - $82 \mathrm{~kg}$ ) \} were randomly recruited for a four-way, four periods, single dose, randomized crossover study. The subjects, who were non-smokers and nonalcoholic, gave their fully informed consent, and also accepted to cooperate fully throughout the duration of the study. They were advised to avoid the use of any drug 14 days prior to the commencement of the study.

Following an overnight fast, the volunteers received the test and reference (standard) tablets with $200 \mathrm{ml}$ of water in a randomized order with a washout period of 7 days. The volunteers were provided with a standard hunch (low fat meal, FDA approved) [11] $12 \mathrm{~h}$ pre-dose and $4 \mathrm{~h}$ post-dose fasting. Following oral administration of the tablets, venous blood samples $(5 \mathrm{ml}$, after first $0.5 \mathrm{ml}$ had been discarded) from antecubital vein were collected via an intravenous cannula (20 gauge) in heparinized-glass tubes (containing $200 \mu \mathrm{l}$ heparin) at predetermined time intervals $(0,1,2,3,4,6,8,10$ and 12 h) for each protocol. The samples were immediately centrifuged at $1000 \mathrm{~g}$ for $10 \mathrm{~min}$ at room temperature $\left(32^{\circ} \mathrm{C}\right)$ to obtain plasma that was stored in labelled Eppendorf tubes in a freezer at $-20{ }^{\circ} \mathrm{C}$ until quantitative bioanalysis by HPLC.

\section{Analysis of metoprolol samples by HPLC}

The quantitative determination of metoprolol tartrate in dissolution and plasma samples was performed by HPLC method $[3,12]$. The HPLC (Isocratic HPLC, Agilent, California, USA) was connected to UV/Vis detector (Agilent, USA) operated at $273 \mathrm{~nm}$ and Hypersil ODS-C18 column $(250 \mathrm{~mm} \times 4.6$ $\mathrm{mm}$ internal diameter, particle size $5 \mathrm{~mm}$; Agilent, USA) operated at $27^{\circ} \mathrm{C}$. The HPLC system was operated with ChemStation software. A degassed mixture of acetonitrile and triple distilled water containing $0.4 \%$ of triethylamine $(\mathrm{pH}$ adjusted to 3.6 with $5 \%$ ortho-phosphoric acid) in the ratio of $15: 85$ was employed as mobile phase, and eluted at a flow rate of $1.0 \mathrm{~mL} / \mathrm{min}$. Total run time for each sample was set at $15 \mathrm{~min}$. Tramadol hydrochloride, as the internal standard, showed no interference with the peaks of metoprolol. The validation parameters [3.12] for the method were also determined (Table 1) according to international guidelines [13]. A calibration curve $(n=7)$ was constructed for the determination of metoprolol in the concentration of $20-200 \mathrm{ng} / \mathrm{ml}$.

\section{Data analysis}

Experimental results were expressed as mean \pm standard deviation (SD). Based on the non-compartment model approach, the values of $\mathrm{C}_{\max }$ (maximum drug concentration in plasma), $t_{\max }$ (time to reach peak concentration), AUC (area under the curve), $\mathrm{K}_{\mathrm{e}}$ (elimination rate constant), $\mathrm{t}_{1 / 2}$ (biological 
half life) and MRT (mean residence time) were measured from plasma metoprolol concentration versus time profiles for each volunteer, using Microsoft Excel, 2007 [1].

The significance of difference between various pharmacokinetic parameters was evaluated by Analysis of Variance (ANOVA) using software, SPSS version 13.0 [1]. The level of significance was set at 0.05 . As same doses of reference and test formulations were given, the relative bioavailability ( $F$ \%) was calculated by dividing In-transformed $\mathrm{C}_{\max }, \mathrm{AUC}_{0-\mathrm{t}}$ and $\mathrm{AUC}_{0 . \infty}$ of test formulation with the $\mathrm{C}_{\max }$, In-transformed $\mathrm{AUC}_{0-\mathrm{t}}$ and $A \cup C_{0 . \infty}$ of reference formulation, respectively. Two compared formulations were considered bioequivalent if the $90 \%$ class intervals (Cls) for these ratios lie between 80 and $125 \%$ [1].

\section{RESULTS}

\section{Validation data}

The coefficient of regression $\left(R^{2}\right)$ of metoprolol calibration curve was 0.9986 . Intra- and inter-day RSD for metoprolol in plasma was $<4 \%$ while intra- and inter-day accuracy was $>95 \%$, as shown in Table 1 . These values indicate that the method used has high repeatability and precision for metoprolol analysis.

\section{Physicochemical properties of metoprolol tablets}

The weight variation, hardness, friability, disintegration, and dissolution for all formulations were within allowed limits of USP [7].

Copolymer concentration influenced the release behavior of metoprolol tablets. As the polymer ratio was increased from $\mathrm{T} 1$ to $\mathrm{T} 3$, the release of metoprolol from formulations decreased. Drug release was very slow in $\mathrm{pH}$ 1.2 and $\mathrm{pH} 4.5$ dissolution media; in contrast, cumulative drug release range from about 56 - $71 \%$ in $\mathrm{pH} 7.0$ media, regardless of the polymer concentration. The best-fit kinetic model for the dissolution data of the test formulations was zero order followed by Higuchi and then first order model [7].

\section{Tolerability of the formulations}

During in vivo study, physical observation by clinician as well as biochemical and hematological tests indicate that there were no significant adverse effects asa result of the administration of any of the formulations, except for mild gastrointestinal disturbance with the reference formulation in one volunteer at the second stage of the study. However, this was not linked to the drug. Also, there were no significant changes in blood, urine and hepatic parameters during the study for any of the formulations. The ECG of all the subjects was normal before and after the study.

Plasma metoprolol concentration versus time profiles of the reference and test formulations are presented in Figure 1 while the derived

Table 1: Intra- and inter-day precision and accuracy profiles (mean \pm SD, $n=3$ ) for HPLC method used in sample analysis

\begin{tabular}{|c|c|c|c|c|c|c|}
\hline \multirow{2}{*}{$\begin{array}{l}\text { Added } \\
\text { concentration } \\
(\mathrm{ng} / \mathrm{mL})\end{array}$} & \multicolumn{3}{|c|}{ Intra-day } & \multicolumn{3}{|c|}{ Inter-day } \\
\hline & $\begin{array}{l}\text { Detected } \\
\text { concentration } \\
(\mathrm{ng} / \mathrm{mL})\end{array}$ & $\begin{array}{l}\text { Precision } \\
\text { (R.S.D. }{ }^{a} \\
\text { (\%) }\end{array}$ & $\begin{array}{l}\text { Accuracy } \\
\text { (Bias, \%) }\end{array}$ & $\begin{array}{l}\text { Detected } \\
\text { concentration } \\
{ }^{c}(\mathrm{ng} / \mathrm{mL})\end{array}$ & $\begin{array}{l}\text { Precision } \\
\text { R.S.D. }{ }^{C} \text { (\%) }\end{array}$ & $\begin{array}{l}\text { Accuracy }{ }^{b} \\
\text { (Bias, \%) }\end{array}$ \\
\hline 20 & $19.87 \pm 0.50$ & 2.53 & -0.63 & $19.87 \pm 1.29$ & 6.47 & -0.63 \\
\hline 100 & $100.79 \pm 0.44$ & 0.43 & 0.79 & $100.79 \pm 1.37$ & 1.36 & 0.79 \\
\hline 200 & $199.22 \pm 0.51$ & 0.26 & -0.39 & $198.88 \pm 0.68$ & 0.34 & -0.56 \\
\hline
\end{tabular}

${ }^{b}$ Accuracy (bias, \%) $=($ detected concentration - added concentration $) /($ added concentration $) \times 100$

${ }^{c}$ Precision (R.S.D, \%) - (standard deviation / mean) x 100 
pharmacokinetic parameters are shown in Table 2. $C_{\max }$ (mean $\pm \mathrm{SD}, \mu \mathrm{g} / \mathrm{ml}$ ) for the reference, T1, T2, and T3 was $190.64 \pm$ $11.84,144.18 \pm 14.55,133.50 \pm 13.65$ and $129.07 \pm 17.13$, respectively, while $\mathrm{AUC}_{0-\mathrm{t}}$ $(\mu \mathrm{g} . \mathrm{h} / \mathrm{ml})$ was $1423.46 \pm 21.81,849.89 \pm$ 19.86, $857.04 \pm 14.86$ and $823.82 \pm 13.28$, respectively. $\quad \mathrm{AUC}_{0-\alpha} \quad(\mu \mathrm{g} . \mathrm{h} / \mathrm{ml})$ for the reference, T1, T2, and T3 was $1675.18 \pm$ 19.57, $927.35 \pm 20.09,1028.79 \pm 24.93$ and $999.54 \pm 17.69$, respectively, and $t_{\max }$ (h) 4.00 \pm 0.45 , and $6.00 \pm 0.38,6.00 \pm 0.50$ and 6.00 \pm 0.43 , respectively. The bioavailability of the reference standard was significantly higher $(p$ $<0.05$ ) that of the test samples. MRT data indicate that the test formulations remained for longer in the GIT than the reference formulation.

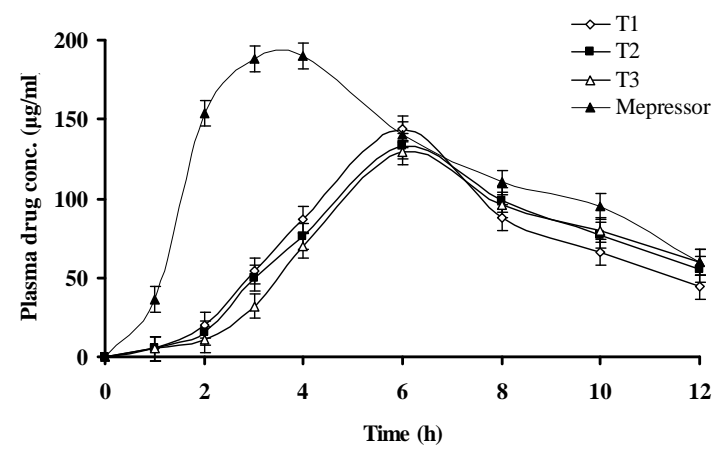

Figure 1: Plasma metoprolol concentration versus time plots after administration of $200 \mathrm{mg}$ dose each of reference and test formulations $(n=28)$

\section{Bioequivalence analysis}

To analyze bioequivalence, the $90 \%$ class intervals for the ratios of the In-transformed $\mathrm{C}_{\text {max }}, \mathrm{AUC}_{0-\mathrm{t}}$ and $\mathrm{AUC}_{0-\alpha}$ for the reference, $\mathrm{T} 1, \mathrm{~T} 2$, and T3 were evaluated and are presented in Table 2 . These results lie in the pre-determined range of bioequivalence (80 to $125 \%$ ), indicating bioequivalence between the two formulations (Table 2).

\section{DISCUSSION}

Copolymer concentration influenced the release behavior of metoprolol tablets. This is due to the acid-resistant property of the polymer matrix which increases as polymer content rose, leading to decrease in metoprolol [7]. This is a consequence of the fact that higher polymer concentration produces larger particles with proportionately less drug. The slower drug release at $\mathrm{pH} 1.2$ and $\mathrm{pH} 4.5$ dissolution media is a result of the fact that Eudragit $^{\circledR} \quad \mathrm{FS}$ is $\mathrm{pH}$-sensitive copolymer that only begins to dissolved at $\mathrm{pH}$ 6.0 [7]. In pH 7.0 medium, the polymer readily dissolves, creating channels in the microparticle coating and thus, facilitating faster drug release [7].

$T_{\max }$ among all the developed (test) formulations was not significantly $(p>0.05)$ different from each other but were significantly $(p<0.05)$ less than that of the reference. The significantly lower values of $\mathrm{C}_{\text {max }}, \quad \mathrm{AUC}_{0-\mathrm{t}}$ and $\mathrm{AUC}_{\mathrm{t}-\infty}$ of the test formulations, compared to those of the reference can be attributed to the coclonic release pattern of the latter, since after departure from the stomach, the colonic coating prevents drug release for an additional $2 \mathrm{~h}$ approximately, compared to the reference formulation. This is buttressed by the higher values of $t_{\max }$ and MRT fortest formulations.

The reference formulation has significantly different bioavailability from that of the test formulations. Metoprolol is a basic drug. Since basic drugs exhibit higher absorption in basic conditions such as the colon, bioavailability from test (colonic) formulations should be higher than that of the reference but the results indicate the reverse.

The possible reason for this unexpected result may be the loss of unreleased drug through feces due to stronger bonding between metoprolol and the polymer. However, stool analysis would need to be conducted to confirmthis. Consequently, it is one of the limitations of this study that the stool analysis and frequency has not been studied. However, this limitation will be sorted out in the future projects.

Trop J Pharm Res, April 2012;11 (2);285 
Table 2: Pharmacokinetic parameters and comparative bioavailability (standard deviation or range in brackets) of sustained release tablets (reference) and developed colonic tablets (T1, T2 and T3) of metoprolol tartrate following administration of a single oral dose of $200 \mathrm{mg}$ to 28 healthy human volunteers

\begin{tabular}{|c|c|c|c|c|}
\hline Parameter & Reference & T1 & T2 & T3 \\
\hline$t_{\max }(h)$ & $4(0.45)$ & $6(0.38)$ & $6(0.5)$ & $6(0.43)$ \\
\hline MRT (h) & $5.78(0.43)$ & $6.72(0.43)$ & $7.03(0.43)$ & $7.23(0.43)$ \\
\hline $\mathrm{C}_{\max }(\mu \mathrm{g} / \mathrm{ml})$ & $190.64(11.84)$ & $144.18(14.55)$ & 133.50 (13.65) & 129.07 (17.13) \\
\hline $\mathrm{AUC}_{0-\mathrm{t}}(\mu \mathrm{g} \cdot \mathrm{h} / \mathrm{ml})$ & $\begin{array}{l}1423.46 \\
(21.81)\end{array}$ & $849.89(19.86)$ & 857.04 (14.86) & $823.82(13.28)$ \\
\hline $\mathrm{AUC}_{0-\infty}(\mu \mathrm{g} \cdot \mathrm{h} / \mathrm{ml})$ & $\begin{array}{l}1675.18 \\
(19.57)\end{array}$ & 927.35 (20.09) & $1028.79(24.93)$ & 999.54 (17.69) \\
\hline $\begin{array}{l}\text { Ratio of } \mathrm{Ln} \mathrm{C}_{\max } \\
(\%)(90 \% \mathrm{Cl}) \text {, } \\
\text { range }\end{array}$ & - & $\begin{array}{l}94.63 \\
(93.91-95.34)\end{array}$ & $\begin{array}{l}93.16 \\
(92.45-93.87)\end{array}$ & $\begin{array}{l}92.45 \\
(91.58-93.32)\end{array}$ \\
\hline $\begin{array}{l}\text { Ratio of Ln } \\
\text { AUC }_{0-\mathrm{t}} \\
(\%)(90 \% \mathrm{Cl})\end{array}$ & - & $\begin{array}{l}92.90 \\
(92.77-93.02)\end{array}$ & $\begin{array}{l}93.01 \\
(92.90-93.12)\end{array}$ & $\begin{array}{l}92.47 \\
(92.38-92.56)\end{array}$ \\
\hline $\begin{array}{l}\text { Ratio of Ln } \\
\text { AUC }_{0-\infty} \\
(\%)(90 \% \mathrm{Cl})\end{array}$ & - & $\begin{array}{l}92.03 \\
(91.93-92.14)\end{array}$ & $\begin{array}{l}93.43 \\
(93.32-93.54)\end{array}$ & $\begin{array}{l}93.04 \\
(92.95-93.14)\end{array}$ \\
\hline
\end{tabular}

\section{Limitations of the study}

The bioavailability and pharmacokinetic study was carried out in 28 young healthy fasting male volunteers. To more closely simulate actual clinical situation, the study shouldd have been conducted in the fed state using a larger sample size and multiple dosing, as well as females, children, old and ill volunteers in the sample population. Stool analysis and frequency should also be studied but this was not done.

\section{CONCLUSION}

It can be concluded from this single-dose study that the reference and test formulations met the predetermined criteria for bioequivalence in the young healthy fasting male human subjects as the bioequivalence factor lie in the pre-determined limits for bioequivalence. Thus the two formulations can be considered bioequivalent. The two formulations were also well tolerated.

\section{REFERENCES}

1. Shargel L, Wu-Pong $S$, Yu ABC. Applied biopharmaceutics and pharmacokinetics. $5^{\text {th }}$
Edition. The Mc-Graw-Hill, New York, USA, 2005.

2. Hardman JG, Limbird LE. $10^{\text {th }}$ Ed. McGraw-Hill, Medical Publishing Division, New York, 2001, p 1125.

3. Aqil M, Ali A, Ahad A, Sultana Y, Najmi AK, Saha N. $A$ validated HPLC method for estimation of metoprolol in human plasma. Acta Chromatogr 2007; 19: 130-140.

4. Nellore RV, Rekhi GS, Hussain AS, Tillman GL, Augsburger LL. Development of metoprolol tartrate extended-release matrix tablet formulations for regulatory policy consideration. J Control Release 1998; 50: 247-256.

5. Marvola M, Nykänen P, Rautio S, Isonen N, Autere $A M$. Enteric polymers as binders and coating materials in multiple-unit site-specific drug delivery systems. Eur J Pharm Sci 1999; 7: 259-267.

6. Ibekwe BC, Basit WA, Parsons GE. A scintigraphic study to assess the fate of colonic drug delivery system. AAPS Pharm Sci 2003a; 5: T3035.

7. Rasool F, Ahmad M, Murtaza G, Khan HMS, Khan SA, Hussain I. Eudragit ${ }^{(}$FS based colonic microparticles of metoprolol tartrate. Accepted for publication in Acta Pol Pharm-Drug Res, 2012; 69: 347-353.

8. USP30-NF25. The official compendium of standards. The United States Pharmacopoeial Convention, 2007.

9. World Medical Association Declaration of Helsinki. Ethical principles of medical research involving human subjects. http://www.wma.net/en/30pub lications/10plicies/b3/index.html. Accessed September 3, 2008.

Trop J Pharm Res, April 2012;11 (2);286 
10. European Medicines Agency. ICH Topic E 6 (R1) Guideline for Good Clinical Practice. Step 5. Note for guidance on good clinical practice (CPMP/ICH/135/95). www.ema.europa.eu/pdfs /human/ich/013595en.pdf. Accessed January 2, 2009.

11. U.S. Department of Health and Human Services. Guidance for industry: Modified release solid oral dosage forms scale-up and post-approval changes: chemistry, manufacturing, and controls, in vitro dissolution testing, and in vivo bioequivalence documentation. Center for drug Evaluation and Research, Food and Drug Administration. Rockville, MD, 1995.
12. Rasool F, Ahmad M, Murtaza G, Khan HMS, Khan SA, Khiljee S, Zaman MQU. Metoprolol tartrate-ethylcellulose tabletted microparticles: development of a validated in vitro-in vivo correlation. WASIT. 2010; 63: 140-143.

13. U.S. Department of Health and Human Services Food and Drug Administration Center for Drug Evaluation and Research (CDER) Center for Veterinary Medicine (CVM). Guidance for Industry Bioanalytical Method Validation. www.fda.gov/downloads/Drugs/.../Guidances/u cm070107.pdf. Accessed January 2, 2008. 